\title{
RENAL CELL CARCINOMA WITH THROMBUS IN THE INFERIOR VENA CAVA: EXTRACORPOREAL CIRCULATION AND DEEP HYPOTHERMIA WITHOUT OPEN-CHEST SURGERY
}

\author{
CARLOS A. L. D'ANCONA, ORLANDO PETRUCCI JR., RODRIGO OTSUKA \\ Fundação Centro Médico de Campinas, Campinas, São Paulo, Brasil
}

\begin{abstract}
Introduction: Renal cell carcinoma with thrombus in the inferior vena cava and no apparent metastasis requires immediate surgical treatment. Over the last few years, extracorporeal circulation with deep hypothermia and total circulatory arrest have played an increasingly important role in the treatment of diseases not associated with primary cardiovascular disorders, such as cavoatrial tumor thrombus in uterine tumors, adrenal tumors, Wilms' tumor, as well as renal cell carcinoma.

Case Report: A 78-year-old patient with renal cell carcinoma and tumoral thrombus in the inferior vena cava and above the supra-hepatic veins underwent right radical nephrectomy and removal of the thrombus from the vena cava with extracorporeal circulation and deep hypothermia with total circulatory arrest without opening the chest. The patient presented good post-operative evolution.
\end{abstract}

Key words: kidney neoplasms; vena cava, inferior; thrombus; nephrectomy; extracorporeal circulation Int Braz J Urol. 2005; 31: 49-50

\section{INTRODUCTION}

When not associated with metastasis, the surgical treatment of renal cell carcinoma with tumoral thrombus in the inferior vena cava (IVC) presents good results that increase the quality of life and survival (1). However, this is a very difficult technical procedure that involves morbidity. We present a case of right radical nephrectomy with extracorporeal circulation, total circulatory arrest with profound hypothermia, without open-chest surgery.

\section{CASE REPORT}

A 78-year-old male patient presented a clinical history of poor health for 3 months. The abdominal ultrasound revealed a solid lesion in the right kidney with thrombus in the IVC. Magnetic resonance imaging confirmed a kidney tumor with level-III thrombus in the IVC extending up to the right atrium and with no evidence of metastasis (Figure-1). The chest X-ray and bone scintigraphy were normal. The surgical approach was through a Chevron incision. The falciform ligament was incised, the liver was pushed inferiorly and the pericardium was opened with the insertion of the diaphragm below the xyfoid appendix. The pericardial window allowed access to the IVC above the diaphragm and permitted cardiac defibrillation. A radical nephrectomy was performed, followed by extracorporeal circulation with deep hypothermia and total circulatory arrest without opening the chest.

Extracorporeal circulation was established by introducing a cannula in the right femoral artery, right femoral and subclavian vein. At $20^{\circ} \mathrm{C}$ body temperature, circulatory arrest was commenced and infra-hepatic as well as supra-hepatic longitudinal cavotomy extending to the right atrium were initiated. The 


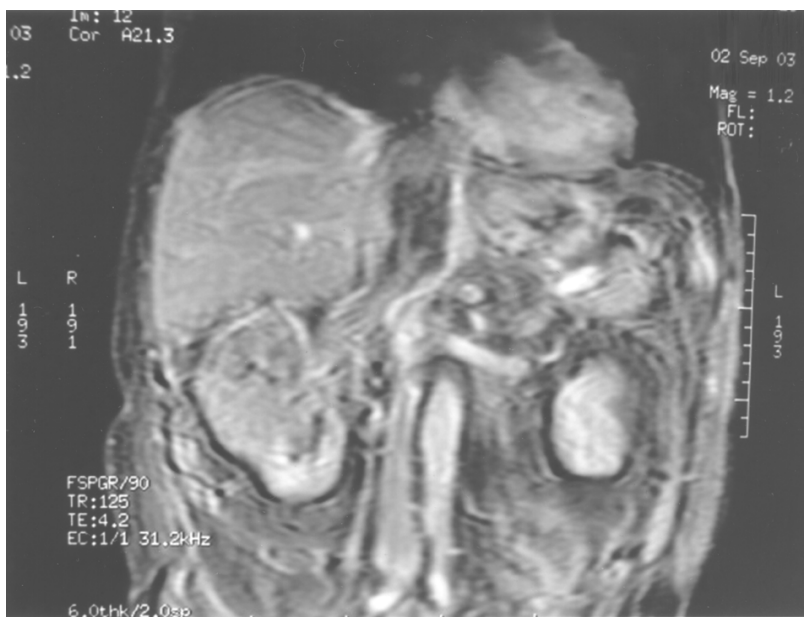

Figure 1 - Magnetic resonance imaging demonstrating right kidney tumor and level-III (atrial) thrombus in the inferior vena cava.

thrombus was completely extracted. Aortic clipping and cardioplegic solutions were not utilized in this procedure.

During re-warming, the heart was defibrillated at a temperature of $30^{\circ} \mathrm{C}$ and no difficulties were encountered in discontinuing extracorporeal circulation. The duration of the cardiac arrest was 18 minutes. The patient was discharged from hospital on the eighth post-operative day and is currently in good general condition.

\section{COMMENTS}

Renal cell tumors with thrombus in the IVC without metastasis require immediate surgical treatment. As yet, there is no consensus regarding the surgical technique of choice, but studies demonstrate that extracorporeal circulation improves operative conditions and reduces surgical morbidity (2). The choice of a circulatory support technique consisting of either normothermic perfusion with venous drainage or total circulatory arrest with profound hypothermia has not been defined (3). When open-chest surgery is avoided, there is a reduction in post-operative complications. The main variables to be considered when choosing this method are: duration of surgery, technical intra-operative difficulties, the size of the tumor and thrombus, as well as the localization and the surgeon's personal preference. In this case, we chose total circulatory arrest with deep hypothermia as the surgical field would provide better visibility of the vascular anatomy for complete extraction of the thrombus. The pericardial window provides access to the IVC and atrium as well as allowing defibrillation of the heart for the re-establishment of normal coordinated heartbeats. Adverse post-operative effects of this procedure are transitory if the duration of hypothermia is less than 40 minutes. The return to routine activities after a reduced period of hospitalization indicates that this could be an important method for re-section procedures of renal tumors with thrombus in the supra-hepatic vena cava.

\section{REFERENCES}

1. Ciancio G, Vaidya A, Savoie M, Soloway M: Management of renal cell carcinoma with level III thrombus in the inferior vena cava. J Urol. 2002; 168: 1374-7.

2. Bissada NK, Yahkout HH, Babanouri A, Elsalamony T, Fahmy W, Gunham M, et al.: Long-term experience with management of renal cell carcinoma involving the inferior vena cava. Urology. 2003; 61: 89-92.

3. Beltz MS, Pae WE Jr, Belis JA: Application of retrograde cerebral perfusion and moderate systemic hypothermic circulatory arrest for cavoatrial tumor resection. Tech Urol. 1999; 5: 87-91.

Received: July 5, 2004

Accepted after revision: October 10, 2004 